\title{
PCR Differential Display Identifies a Rat Brain mRNA That Is Transcriptionally Regulated by Cocaine and Amphetamine
}

\author{
James Douglass, Audra A. McKinzie, and Pastor Couceyro \\ Vollum Institute, Oregon Health Sciences University, Portland, Oregon 97201
}

Neuronal plasticity associated with both short- and longterm administration of psychomotor stimulants involves alterations in specific patterns of gene expression. In order to screen for brain region specific mRNAs which are transcriptionally regulated by acute cocaine and amphetamine, PCR differential display was employed. This approach identified a previously uncharacterized mRNA whose relative levels in the striatum are induced four- to fivefold by acute psychomotor stimulant administration. Isolation and characterization of corresponding cDNA clones resulted in complete nucleotide sequence analysis, including prediction of the encoded protein product. Alternate polyA site utilization in the predicted $3^{\prime}$ noncoding region results in the appearance of an RNA doublet, approximately 700 and 900 bases in length, following Northern analysis. A presumed alternate splicing event further generates diversity within the transcripts, and results in the presence or absence of an in-frame 39 base insert within the putative protein coding region. As a result, the predicted translation products are either 129 or 116 amino acids in length. A common hydrophobic leader sequence at the amino terminus is present within each predicted polypeptide, suggesting that the protein product is targeted for entry into the secretory pathway. Basal expression of the RNA doublet is limited to neuroendocrine tissues, further implying that the protein product plays a functional role in both neuronal and endocrine tissues.

[Key words: cocaine, neuronal plasticity, PCR differential display, cDNA cloning, neuroendocrine, neuromodulator]

Cocaine is a psychomotor stimulant affecting mammalian physiology and behavior following both acute and chronic patterns of administration. These adaptive changes result in the establishment of physical states representing tolerance, dependence, sensitization, and withdrawal. Pharmacologically, the drug acts by inhibiting the synaptosomal uptake of catecholamines (including dopamine and norepinephrine), and 5-HT (Gawin, 1991;

Received Aug. 17, 1994; revised Oct. 4, 1994; accepted Oct. 7, 1994.

We thank Dr. Geoffrey Murdoch (OHSU) for supplying total RNA from human brain, and Drs. Richard Simerly (Oregon Regional Primate Research Center) and Marty Mortrud (OHSU) for valuable assistance with in situ histochemical analysis. The work was funded by Public Health Service Grant DA04154 (to J.D.) from the National Institute on Drug Abuse. P.C. was the recip ient of a predoctoral fellowship from NIDA Training Grant T32-DA07262.

Correspondence should be addressed to Dr. James Douglass, Vollum Institute L474, Oregon Health Sciences University, 3181 SW Sam Jackson Park Road, Portland, OR 97201

Copyright (C) 1995 Society for Neuroscience $\quad 0270-6474 / 95 / 152471-11 \$ 05.00 / 0$
Koob, 1992). Modulation of dopaminergic neurotransmission within the striatum, for example, is believed to underlie the rewarding and reinforcing properties associated with cocaine administration (Kuhar and Boja, 1991).

It is currently hypothesized that cellular plasticity within specific neural circuits underlies the behavioral and physiological alterations associated with psychomotor stimulant administration (for review, see Nestler, 1992). One such type of plasticity occurs at the nuclear level, and involves the regulated expression of specific sets of genes. For example, cocaine selectively regulates the pattern of expression of immediate early genes (IEGs), particularly those belonging to the Fos and Jun (i.e., AP-1) family of transcriptional regulatory factors, within the brain. Furthermore, such transcriptional regulation appears to be localized to those brain regions regulated by catecholaminergic input. For example, it is now firmly established that acute administration of cocaine induces expression of c-fos and jun $B$ mRNA in the rat striatum (Graybiel et al., 1990; Dragunow et al., 1991; Young et al., 1991; Hope et al., 1992; Nguyen et al., 1992). The cerebellum also represents a brain structure in which c-fos mRNA levels are selectively elevated following acute cocaine administration (Clark et al., 1992; Iadarola et al., 1993). Cocaine produces an increased sensitivity to sensory stimuli, and the cerebellar cortex is believed to play a significant role regarding such physiological alterations. By contrast, the hippocampus represents a transcriptionally quiescent brain structure following acute administration of psychomotor stimulants. Thus, such brain region spccific transcriptional changes associated with psychomotor stimulant administration may be relevant to reinforcement and addiction.

An important area of current research involves identification of additional psychomotor stimulant regulated genes. Identification of such genes will certainly increase our understanding of the molecular events underlying both short- and long-term cellular changes resulting from administration of psychomotor stimulant drugs. In the study described here, PCR differential display (Liang and Pardee, 1992; Bauer et al., 1993; Liang et al., 1993) was used to screen for such psychomotor stimulantregulated transcripts in specific brain structures. Radiolabeled PCR product banding patterns were compared which represent rat cerebellar, striatal and hippocampal RNA isolated $60 \mathrm{~min}$ following acute administration of saline, cocaine, or amphetamine. Those specific PCR bands whose relative levels are altered by drug administration thus potentially represent species of mRNA which are transcriptionally regulated by acute administration of psychomotor stimulants. One such PCR product was identified, leading to determination of the corresponding mRNA 
sequence through cDNA cloning, transcriptional patterns of the mRNA via Northern blot and in situ histochemical analysis, and translational properties of the transcript both in vitro and in vivo.

\section{Materials and Methods}

Animals, tissue and RNA preparation, and pharmacological protocols. Adult $90 \mathrm{~d}$ old male Sprague-Dawley rats were kept under a $12 \mathrm{hr}$ light/12 hr dark cycle and given food and water ad libitum. For acute psychomotor stimulant studies, a single dose of cocaine $(20 \mathrm{mg} / \mathrm{kg})$ or amphetamine $(6 \mathrm{mg} / \mathrm{kg})$ dissolved in saline was given intraperitoneal (i.p.); saline injections served as control. The animals were sacrificed 1 $\mathrm{hr}$ after injection via halothane anesthetization to unconsciousness $(<1$ $\min$ ) and decapitation. The whole brain was removed and rinsed in icecold PBS for 1 min prior to dissection. Cerebellum, striatum, and hippocampus were dissected and immediately stored on dry ice. All tissue samples were stored at $-70^{\circ} \mathrm{C}$.

For Northern blot RNA tissue distribution studies, adult $90 \mathrm{~d}$ old Sprague-Dawley rats were sacrificed as described. Brain dissections were performed as described (Glowinski and Iversen, 1966). Total RNA from various brain regions and peripheral tissues was immediately prepared using a modified acid phenol technique (Chomczynski and Sacchi, 1987), with final concentration determined spectrophotometrically. Human brain (with a negative drug toxicology profile) total RNA was graciously supplied by Dr. Geoffrey Murdoch, Department of Pathology, Oregon Health Science University.

$P C R$ differential display. Isolation of total RNA from rat cerebellum, striatum, and hippocampus was performed as described. Following the determination of concentration, RNAs from the aforementioned brain regions were then pooled from 6-10 animals receiving either saline, cocaine, or amphetamine injections. Reverse transcription was performed essentially as described previously (Iiang and Pardee, 1992) using $T_{11} V N$ oligonucleotides as primers. The only significant modification involved a primer preannealing step at $35^{\circ} \mathrm{C}$ for $60 \mathrm{~min}$ prior to initiation of reverse transcription by the addition of dNTPs and MMLV reverse transcriptase. Reverse transcription reactions were then subjected to PCR in the presence of ${ }^{35} \mathrm{~S}-\alpha$-dATP and oligonucleotides specifically designed for differential display (Liang and Pardee, 1992). Final concentrations of $1 \mathrm{mM} \mathrm{MgCl}$ and $20 \mu \mathrm{M}$ dNTPs were found to be optimal for these two reagents. The 5' PCR oligonucleotide $(10-\mathrm{mer}$, $50 \% \mathrm{G} / \mathrm{C}$ content) was present at a final concentration of $0.5 \mathrm{pmol} / \mu \mathrm{l}$, while the $3^{\prime} \mathrm{PCR}$ oligonucleotide $\left(\mathrm{T}_{11} \mathrm{VN}\right)$ was present at a final concentration of $2.4 \mathrm{pmol} / \mu \mathrm{l}$. PCR conditions employing a Perkin Elmer Cetus GeneAmp PCR System 9600 thermocycler were 40 cycles of denaturation at $94^{\circ} \mathrm{C}$ for $30 \mathrm{sec}$, primer annealing at $40^{\circ} \mathrm{C}$ for $120 \mathrm{sec}$, and extension at $72^{\circ} \mathrm{C}$ for 30 sec. A final extension reaction was then performed at $72^{\circ} \mathrm{C}$ for $7 \mathrm{~min}$. Radiolabeled reaction products were subjected to high resolution polyacrylamide/urea gel electrophoresis as described (Liang and Pardee, 1992). Psychomotor stimulant regulated PCR products were excised from the gel, reamplified by PCR and subcloned into the pCRII vector (Invitrogen, San Diego, CA) via the T/A cloning procedure. Inserts were analyzed by supercoil dideoxynucleotide sequencing.

cDNA cloning. cDNA clones were isolated from rat striatal and hypothalamic libraries in the lambda vector, ZAPII (libraries purchased from Stratagene, La Jolla, CA). Approximately $5 \times 10^{5}$ clones were plated from each of the aforementioned libraries, and screened under stringent hybridization conditions employing the radiolabeled PCR fragment as a hybridization probe. Hybridization positive clones were plaque purified, the cDNA inserts isolated in phagemid form following superinfection with helper phage, and the inserts sequenced as described. Subsequent nucleotide sequence analysis was performed employing the Wisconsin CGC suite of analytical software. The nucleotide sequence of the full length cDNA has been assigned accession number U10071 in the GenBank database.

Nurthern blot analysis. For Northern blot analysis, total RNA (3-5 $\mu \mathrm{g})$ was separated by electrophoresis on $6 \%$ formaldehyde, $1.2 \%$ agarose gels. The RNA was transferred to Magna NT nylon membranes (Micron Separations Inc., Westboro, MA) by capillary action with 20 $\times$ SSC, followed by UV cross-linking. The membranes were then briefly dipped in $0.3 \mathrm{M}$ sodium acetate, $0.02 \%$ methylene blue to stain the transferred RNA. 28S and 18S rRNA were readily apparent, and served as a means by which to standardize for the amount of RNA contained within each sample. Following removal of stain by boiling in water for $10 \mathrm{~min}$, the membranes were prehybridized for $3-24 \mathrm{hr}$ at $60^{\circ} \mathrm{C}$ in hybridization buffer [5\% SDS, $400 \mathrm{~mm}$ sodium phosphate (7.0), $1 \mathrm{mM}$ EDTA, $1 \mathrm{mg} / \mathrm{ml}$ BSA (fraction V) and $50 \%$ formamide]. The prehybridization buffer was discarded and replaced with fresh hybridization buffer including a specific cRNA hybridization probe. Hybridization procceded for $16-24 \mathrm{hr}$ at $60^{\circ} \mathrm{C}$. Membranes were subsequently washed with $1 \%$ SDS, $0.05 \times \mathrm{SSC}$, and $1 \mathrm{~mm}$ EDTA at $70-75^{\circ} \mathrm{C}$ for $1-4 \mathrm{hr}$. After washing, membranes were exposed multiple times to Kodak XAR-5 film in order to obtain a range of hybridization signal intensities for semiquantitative densitometric analysis. For each RNA sample, autoradiographic signals within the linear range of film sensitivity were digitized using an X-Ray Scanner Corp. model MSF300ZS laser scanner and ADOBE PHOTOSHOP XSF software. Relative intensities were quantified using Image software. RNA doublet signal intensities were standardized against $28 \mathrm{~S}$ or $18 \mathrm{~S}$ rRNA (detected by methylene blue staining), or cyclophilin mRNA (detected by Northern blot analysis employing radiolabeled CRNA as a hybridization prohe).

In situ hybridization. For in situ hybridization analysis, a slightly modified version of the Simmons et al. (1989) protocol was used. Free floating sections were stored in cryoprotectant $(50 \% 0.05 \mathrm{~m}$ sodium phosphate buffer, $\mathrm{pH} 7.3,30 \%$ ethylene glycol, $20 \%$ glycerol) at $-20^{\circ} \mathrm{C}$ for 2-6 weeks. Sections were then mounted onto subbed and poly-Llysine coated slides after three washes (in $0.05 \mathrm{M}$ sodium phosphate

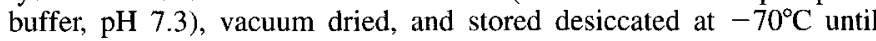
hybridization. Serial sections $30 \mu \mathrm{m}$ thick from three adult SpragueDawley rat brains were cut on a sliding microtome. Whole brain series were collected from prefrontal cortex to the cervical spinal cord, and each section in a series was approximately $270 \mu \mathrm{m}$ from an adjacent section. Hybridization with the same antisense cRNA probe employed for Northern blot analysis was performed at $63^{\circ} \mathrm{C}$, with the most stringent posthybridization wash step performed at $75^{\circ} \mathrm{C}$. Hybridization with a sense RNA probe served as a control for in situ signal specificity. Slides were exposed to CRONEX film (Amersham) for $2 \mathrm{~d}$. They were then dipped in NB-20 emulsion (Kodak) and developed $5 \mathrm{~d}$ thereafter.

To identify specific neuroanatomical structures, adjacent sections were Nissl stained followed by microscopic evaluation. The rat brain atlas of Swanson (1992) was used to identify specific in situ hybridization positive cells and brain nuclei, as well as providing a nomenclature for subsequent labeling. Dr. Richard Simerly (Oregon Regional Primate Research Center) provided expert assistance concerning the identification of hybridization positive brain structures.

Plasmid constructs and riboprobe synthesis. Analysis of relative RNA doublet levels was carried out with an antisense cRNA probe following subcloning of the cDNA fragment representing nucleotides 42-800 into the plasmid pBSII SK- (Stratagene). A $650 \mathrm{bp}$ fragment (35-685, PstI/HincII) of rat cyclophilin cDNA was also subcloned into pGEM 3Z, with relative cyclophilin mRNA levels serving as internal controls. Radiolabeled ( $\left.{ }^{32} \mathrm{P}-\alpha-\mathrm{UTP}\right) \mathrm{RNA}$ probes were synthesized in vitro using either SP6, T3, or T7 RNA polymerase. Specific activities of cRNA probes were routinely greater than $3 \times 10^{9} \mathrm{cpm} / \mu \mathrm{g}$ plasmid.

Statistical analysis. Normalized values are represented as means \pm standard error unless otherwise stated. Statistical analyses were determined with a one-way analysis of variance (ANOVA) using the Fischer PLSD test as calculated with STATVIEW II software.

\section{Results}

To determine the usefulness of PCR differential display as an approach by which to identify cocaine and amphetamine regulated transcripts, the efficacy of the technique was evaluated by utilizing c-fos specific oligonucleotides capable of generating a PCR product from the rat $\mathrm{c}$-fos transcript (Curran et al., 1987) (Fig. 1A). The observed profile of radiolabeled PCR products shows, as expected, that multiple species of mRNA within the rat cerebellum, striatum and hippocampus can serve as a hybridization target for the two oligonucleotides utilized. A typical reaction generated 50-200 distinct radiolabeled PCR products between 50 and 600 bases in length. Furthermore, the overwhelming majority of PCR products were present at identical levels in these three brain regions isolated from saline, cocaine and amphetamine treated animals. The PCR product representing the c-fos transcript was, however, clearly induced in the striatum and cerebellum from cocaine and amphetamine treated an- 

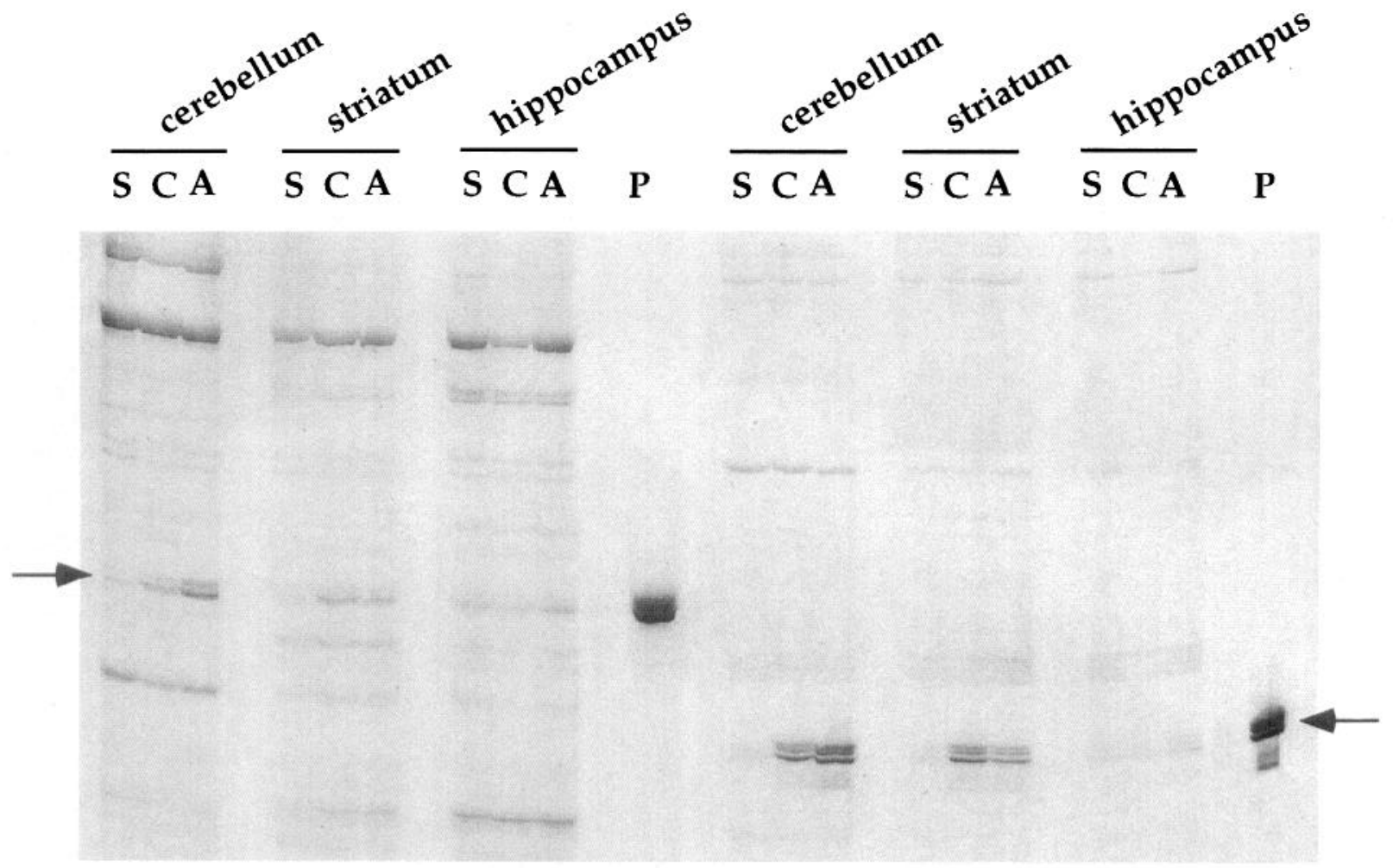

B

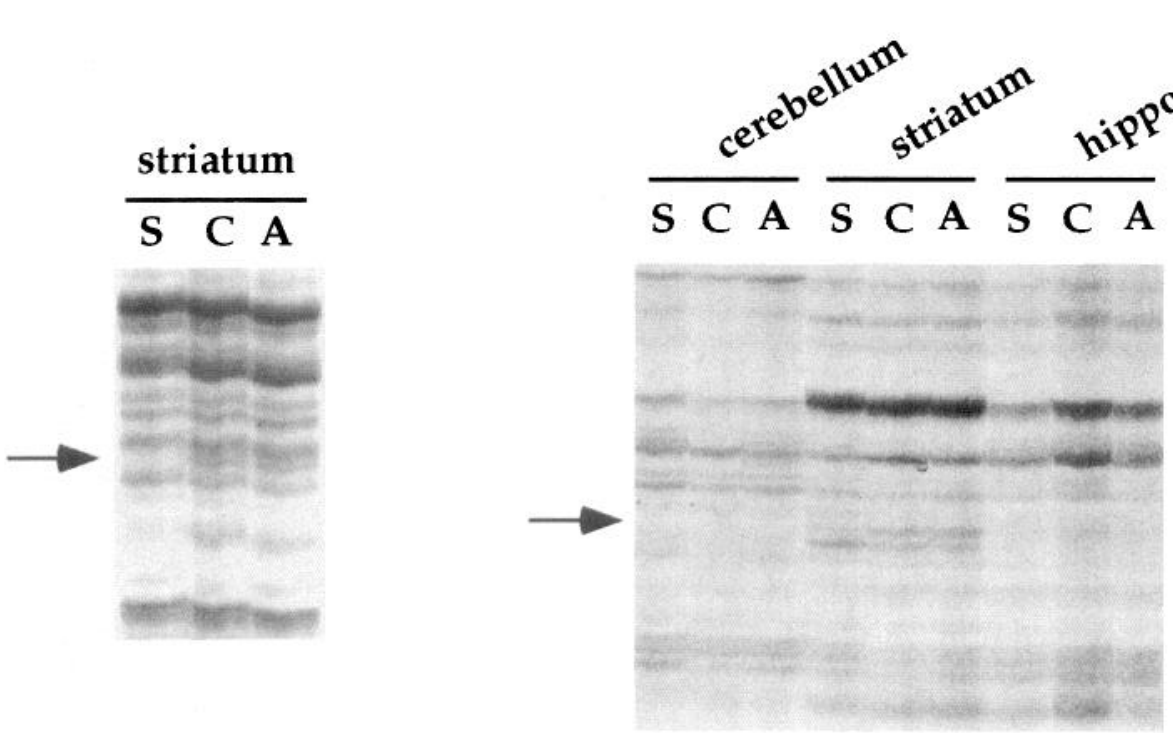

Figure 1. PCR differential display analysis of rat brain RNA following acute administration of psychomotor stimulants. A, Autoradiograph of radiolabeled PCR differential display products using oligonucleotides specific for rat $c$-fos mRNA. Animals received injections of saline $(S)$, 20 $\mathrm{mg} / \mathrm{kg}$ cocaine $(C)$, or $6 \mathrm{mg} / \mathrm{kg}$ amphetamine $(A)$. RNA for reverse transcription/PCR differential display was isolated from the brain regions noted (cerebellum, striatum, and hippocampus). Arrows note specific PCR product representing $c$-fos mRNA. $P$ represents PCR performed on plasmid DNA containing a full length $c$-fos cDNA insert. Left, PCR oligonucleotides were employed to generate a 284 bp $c$-fos product. Right, PCR oligonucleotides were employed to generate a $250 \mathrm{bp} c$-fos product. $B$, Autoradiograph of radiolabeled PCR differential display products using $5^{\prime}$ oligonucleotide ACGTCTCATG and 3' oligonucleotide T 11 GC. Arrow notes a specific PCR product representing a putative striatal, psychomotor stimulant regulated RNA. Left, Initial PCR analysis. Right, Repeated PCR analysis. 
A

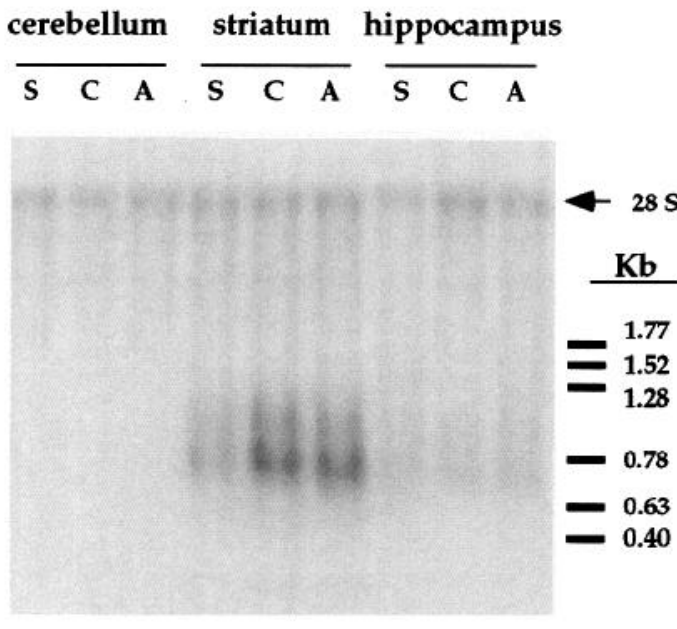

B

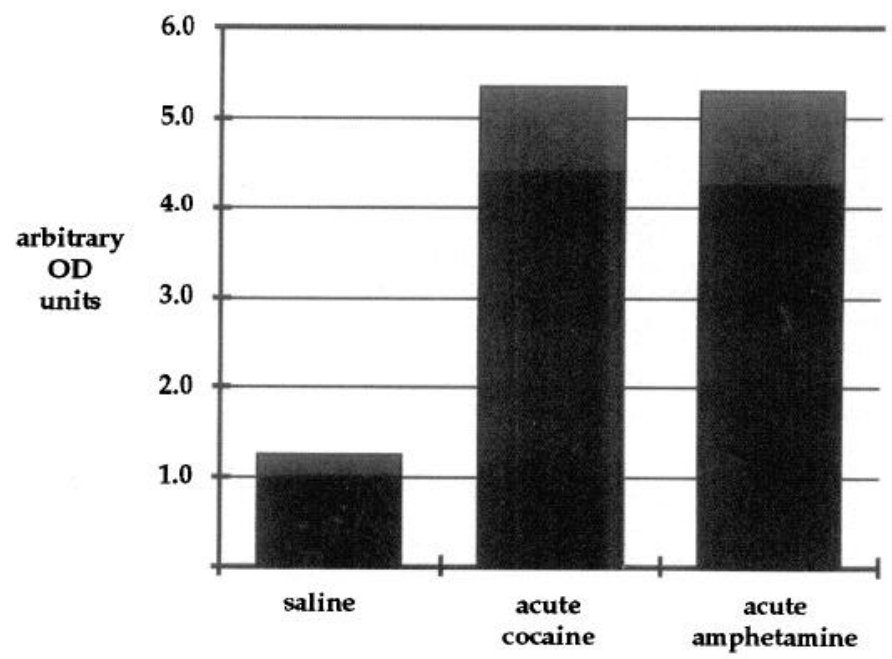

Figure 2. Northern blot analysis employing striatal, psychomotor stimulant induced PCR product as hybridization probe. A, Autoradiograph of Northern blot containing $5 \mu \mathrm{g}$ of total RNA isolated from cerebellum, striatum and hippocampus following a 60 min treatment with saline $(S)$, 20 $\mathrm{mg} / \mathrm{kg}$ cocaine $(C)$, or $6 \mathrm{mg} / \mathrm{kg}$ amphetamine $(A)$. Samples represent pooled RNA from 6-10 individual animals. $B$, Semiquantitative analysis of striatal RNA doublet levels. Striatal RNA from individual animals was subjected to Northern analysis as described, with relative autoradiographic signal intensities determined following densitometric analysis. Error bars represent 1 SEM $(n=4-6)$. Location of RNA size standards is noted, as well as $18 \mathrm{~S}$ and $28 \mathrm{~S}$ rRNA.

imals, with no such induction observed in the hippocampus. The relative levels of the c-fos PCR products were determined by semiquantitative densitometric analysis, and the degree of induction was nearly identical to that determined previously by Northern blot analysis (data not shown). Thus, not only is PCR differential display capable of detecting qualitative differences in relative mRNA levels, but is semiquantitative as well under the PCR conditions employed for this study.

Similar PCR differential display reactions were performed on those RNA samples described above utilizing a set of 12, 3' primers $\left(\mathrm{T}_{11} \mathrm{VN}\right)$ and $8,5^{\prime}$ primers (random 10 -mers, $50 \% \mathrm{G} / \mathrm{C}$ content). The 96 subsequent $\mathrm{PCR}$ reactions resulted in the generation of approximately 12,000-15,000 radiolabeled PCR products, with six to eight bands exhibiting a profile reflective of transcriptional regulation within the striatum by cocaine and amphetamine. Three such bands were subsequently shown to represent c-fos mRNA. One radiolabeled PCR band was chosen for further analysis based on its relatively unique profile of appearance (Fig. $1 B$; the 5' PCR-dd oligonucleotide was ACGTCTCATG, and the $3^{\prime}$ PCR-dd oligonucleotide was $T_{11}$ GC). The relative abundance of this approximately 400 bp PCR product was significantly increased in striatal RNA samples from animals treated acutely with cocaine or amphetamine. No such drug induced increase was observed for the hippocampal RNA samples, and no PCR product was observed in the cerebellar RNA samples regardless of drug treatment. To further characterize this PCR product, the fragment was isolated from a preparative acrylamide/urea gel, subjected to PCR under standard conditions, and subcloned into the vector PCRII via T/A cloning.

To confirm that the cloned PCR product represents a striatal mRNA which is transcriptionally regulated by psychomotor stimulants, the purified DNA fragment was radiolabeled to serve as a hybridization probe for Northern blot analysis (Fig. $2 A$ ). In striatal and hippocampal RNA isolated from saline injected animals, two hybridization positive transcripts were observed which are approximately 700 and 900 bases in length. In the striatum, cocaine and amphetamine treatment increased the relative level of the RNA doublet by four- to fivefold (Fig. 2B), while no such modulation was observed in the hippocampus. Additional Northern blot analysis of RNA isolated from hypothalamus, midbrain/thalamus, hindbrain and cortex also showed no transcriptional regulation by acute cocaine or amphetamine treatment (data not shown). No RNA doublet is observed in cerebellar RNA samples regardless of treatment. Thus, the profile of this RNA within the cerebellum, striatum and hippocampus as determined by Northern blot analysis conforms to that for the corresponding PCR product identified by differential display analysis.

Following confirmation that the aforementioned PCR fragment is derived from a psychomotor stimulant regulated transcript, rat striatal and hypothalamic cDNA libraries were screened under stringent hybridization conditions utilizing the radiolabeled PCR fragment as a hybridization probe. Screening of approximately $1 \times 10^{6}$ recombinant lambda plaques resulted in the isolation and nucleotide sequence characterization of approximately 20 distinct cDNA clones. $5^{\prime}$ RACE was also used to isolate cDNA/PCR products representing the $5^{\prime}$ end of the mRNA. The cDNA sequence representing the approximately 900 base transcript is shown in Figure 3. The cDNA is 840 bases in length, excluding an $(\mathrm{A})_{26}$ tail. The polyA addition recognition sequence, AATAAA, at position 814 directs polyA tail addition at this site. A second species of cDNA clone contained an $(\mathrm{A})_{40}$ tail following nucleotide 579, utilizing the AATAAA element at position 548. Thus, the molecular mechanism underlying the appearance of the RNA doublet appears to be differential polyA site utilization. cDNA nucleotide sequence analysis also uncovered an apparent alternate exon splicing event within the predicted translated region of the RNA. Approximately one-third of the cDNA clones sequenced contained the 39 nucleotides representing those from $179-217$, while the remaining clones did not. Lastly, nucleotides 158 and 556 represent the 5' ends of the two oligonucleotides used in the original PCR differential 
AGCGAGGAAGTCCAGCACCATGGAGAGCTCCCGCCTGCGGCTGCTACCCGTCCTGGGCGC 60

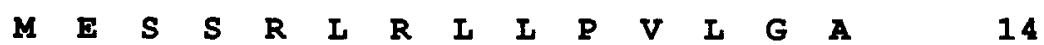

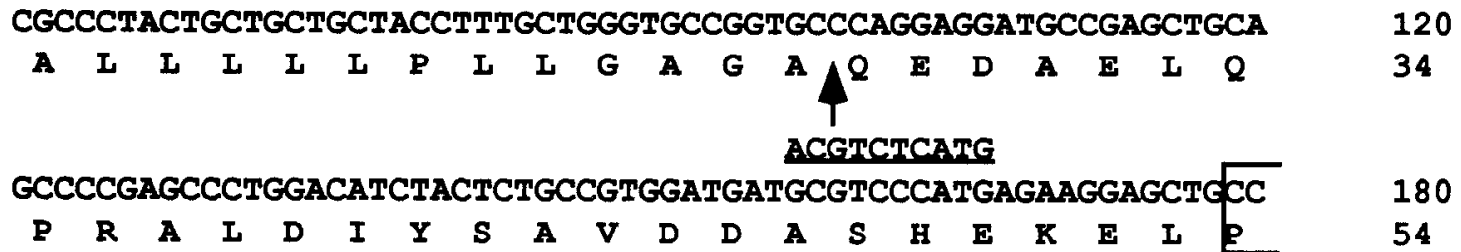

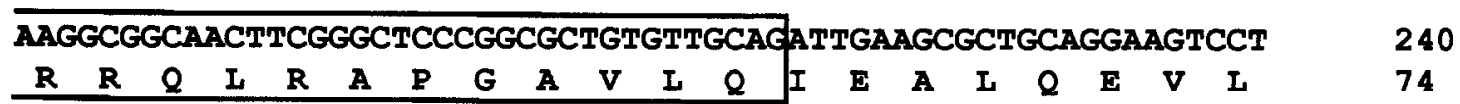

GAAGAAGTCAAGAGTAAACGCATTCCGATCTATGAGAAGAAGTACGGCCAAGTCCCAT 300

$\begin{array}{lllllllllllllllllllllll}K & K & L & K & S & K & R & I & P & I & Y & E & K & K & Y & G & Q & V & P & M & & 94\end{array}$

GTGTGACGCTGGAGAGCAGTGCGCAGTGCGGAAAGGGCCAGGATCGGGAAGTGTGTGA 360

$\begin{array}{lllllllllllllllllllllll}C & D & A & G & E & Q & C & A & V & R & K & G & A & R & I & G & K & I & C & D & & & 114\end{array}$

CTGTCCCCGAGGAACTTCTTGCAATCTTTCCTCTTGAAGTGCTTGTGAAGGGTGACAG $\mathbf{4 2 0}$

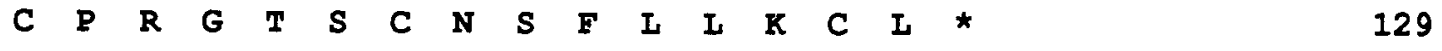

CCTCCTTCGGTTCCATATTTCCTCTTTCCCCTAAAGGAGCGTCTTTTGTCCCTGGAGC $\quad 480$

CGCTTTAACAACAATAAAGTTTGCGTTCCCCCAGAGAGTGGATGGGCTCTTTCCCTGCT $\quad 540$

GCTTCAAATAAAAGATITGATGTTATTGTGTGAAGGACAATACCTTGAATGGTGTTGGT 600

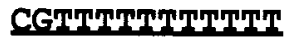

ATGTGTGCAAATATTCTTCTCTCGTTTTATCCACCTGACACATTCTTGTGACCTTTCTG 660

GGAGAAGAGGACTTTCGCTTTAAAATGTATTTTTGTATGTGGCGGTCACAATGAAG $\quad 720$

ATTAGACCTAGTTAATTTTGGAGATGACATCATAACCCGAAAACAAATCACCCCAAAG 780

\section{CAACACAAATGGAGCATGTGCAAATTACACCCAATAAAGCATTTTTGATAATTGCTCAC 840}

Figure 3. Nucleotide and predicted amino acid sequence of cDNA representing the striatal psychomotor stimulant regulated RNA doublet. PolyA addition sites (AATAAA) utilized to generate the approximately 700 base transcript (nuc. 548), and 900 base transcript (nuc. 814) are underlined, with solid triangles representing location of the polyA tail. Also noted is the location of sites at which the $5^{\prime}$ (nucs. 158-167) and $3^{\prime}$ (nucs. 544556) PCR differential display oligonucleotides hybridized. The region representing an alternately spliced 39 nucleotide sequence is boxed (nucs. 179-217). The predicted translational reading frame begins with an ATG at nuc. 20, and extends to the TGA termination site at nuc. 407. An arrow denotes the carboxy-terminal residue of the predicted hydrophobic signal sequence. The presented nucleotide sequence [subsequently to be referred to as CART (cocaine and amphetamine regulated transcript] has been assigned accession number U10071 by GenBank). 
display analysis. Several mismatches are present between the PCR differential display oligonucleotides and the complementary cDNA sequence, as anticipated. The sequence of the original PCR differential display fragment also matches that located between nucleotides 168 and 543 in the cDNA clones.

The first potential translation initiation codon is located at nucleotide 20 . In $90-95 \%$ of the vertebrate transcripts analyzed to date, the first $5^{\prime}$ AUG represents the site for translation initiation (Kozak, 1989). Furthermore, the nucleotide sequence in which this ATG is embedded is similar to that representing a consensus Kozak translation initiation sequence element (GCCGCCRCCATGG). The predicted encoded polypeptide is either 129 or 116 residues in length, depending on the presence or absence of nucleotides 179-217 within the putative protein coding region, respectively. The first 27 residues represent an amino terminal hydrophobic domain conforming to the motif of a signal peptide (Lingappa and Blobel, 1980; van Heijne, 1990), suggesting that the polypeptide may be targeted for entry into the secretory pathway. There are also multiple paired basic amino acid residues located throughout the molecule which could theoretically serve as target sites for posttranslation proteolytic cleavage events (Steiner et al., 1992). One such site is present within the alternately spliced domain encoding residues 54-66, further suggesting that if proteolytic cleavage events did occur, then different peptide end products would be produced from the two distinct primary translation products.

Additional Northern blot analysis was performed to determine the tissue distribution of the RNA doublet. In Figure 4A, RNA from various rat brain regions was analyzed employing a full length radiolabeled antisense cRNA hybridization probe. The major site of synthesis of the RNA doublet is the hypothalamus. Relatively abundant RNA levels are also observed in the thalamus/midbrain, with significantly lower expression observed in the cortex, striatum, hippocampus, and hindbrain. Semiquantitative densitometric analysis of the hybridization signals revealed that hypothalamic RNA levels are approximately 300 fold greater, and midbrain/thalamus RNA levels 10 -fold greater than striatal levels. Analysis of RNA isolated from peripheral tissues (Fig. $4 B$ ) also detected the presence of the RNA doublet in rat eye and adrenal, while no hybridization signal was observed in the other 13 tissues examined. Levels of the RNA doublet in the eye approximate those of the midbrain/thalamus, while adrenal levels are similar to those observed in the striatum. Several additional endocrine tissues were also evaluated for expression of the mRNA doublet (data not shown). No hybridization signal was observed in rat ovary and uterus RNA. However, a robust hybridization signal was observed when pituitary RNA was examined; the relative intensity of the pituitary hybridization signal approximates that observed for the hypothalamus. Expression of the RNA doublet is thus limited to neuroendocrine tissues, with dramatically varied levels of transcriptional expression ohserved throughout the brain.

Further Northern blot analysis also confirmed that the transcript is present in RNA isolated from human brain (Fig. 5). Relatively abundant levels of an approximately 900 base hybridizing transcript are observed in RNA from human hypothalamus, frontal cortex, and midbrain, with lower levels seen in the hippocampus, motor cortex, and striatum. No such hybridization signal was observed in cerebellar RNA. Thus, the pattern of distribution of the transcript in human brain is relatively conserved to that observed for rat brain. However, only a single species of hybridizing RNA is present in human, in con- trast to the doublet RNA band which is consistently observed in rat. The likely explanation for this difference is the lack of a polyA addition site, or recognition of the site, in the human transcript.

Lastly, regional expression of the RNA doublet throughout the adult rat hrain was more precisely determined by in situ histochemical analysis. A subset of hybridization positive regions are presented in Figure 6. For these studies a 790 base cRNA hybridization probe spanning the putative coding region (including the alternately spliced 39 base insert) and 3 ' noncoding region was utilized. The most intense hybridization signals were observed in the Edinger-Westphal nucleus and induseum griseum. Major expression was also seen in the periventricular zone of the hypothalamus (especially the paraventricular and arcuate nuclei) and cells throughout the medial hypothalamus (typified by labeling of the supraoptic nucleus and perifornical region). Within these structures, intense hybridization signals were observed at the single cell level.

Telencephatic hybridization signals were limited to a few areas. Of note was the distribution in the neostriatum where moderate labeling was evident in the ventral region, consisting of the nucleus accumbens and olfactory tubercle. This area of hybridization positive cells stretched along the nucleus accumbens border within striosomes of the ventrolateral caudoputamen. Within the neocortex, moderate labeling was seen only in the primary somatosensory area (layer 4 ) and the piriform area. Intense labeling was observed in the induseum griseum, with the bed nuclei of the stria terminalis and the dorsal blade of the dentate gyrus of the rostral hippocampus exhibiting moderate to weak labeling. Moderately intense hybridization signals were also seen in the amygdaloid complex, particularly in the medial part of the septal nucleus, posterior dorsal part of the medial nucleus, posterior cortical nucleus, and posterior basolateral nucleus.

In the diencephalon, the hypothalamus exhibited the most extensive labeling distribution of any brain region examined. Intense to moderate labeling of cells was evident throughout entire nuclei such as the paraventricular (particularly the parvocellular region), arcuate, and supraoptic nuclei. Moderate labeling was seen in the posterior periventricular nucleus, ventral and medial premammillary nucleus, and lateral aspect of the supermammillary nucleus. Scattered cells in the perifornical region, lateral hypothalamus, and posterior hypothalamus exhibited intense to moderate signals. Within the thalamus, the medial aspect of the zona incerta, ventral half of nucleus reuniens, and lateral habenula were the only structures exhibiting moderate to weakly intense hybridization signals.

The mesencephalon contained the fewest number of hybridization positive cells. However, within this region the EdingerWestphal nucleus exhibited intense labeling. Scattered cells with moderate to weak labeling were also noted in the dorsal periaqueductal gray. The rhombencephalon also contained regions of hybridization positive cells. Both the inferior olive and nucleus of the solitary tract exhibited moderate labeling, where as the locus coeruleus and nucleus incertus showed weak labeling. Scattered cells throughout the $\mathrm{A} 1 / \mathrm{C} 1$ region of the nucleus ambiguus further exhibited moderate labeling.

Hybridization of all aforementioned brain sections with a sense cRNA probe under identical conditions showed no labeling of any of the structures described above. Thus, the hybridization signals which were observed employing the antisense 
A

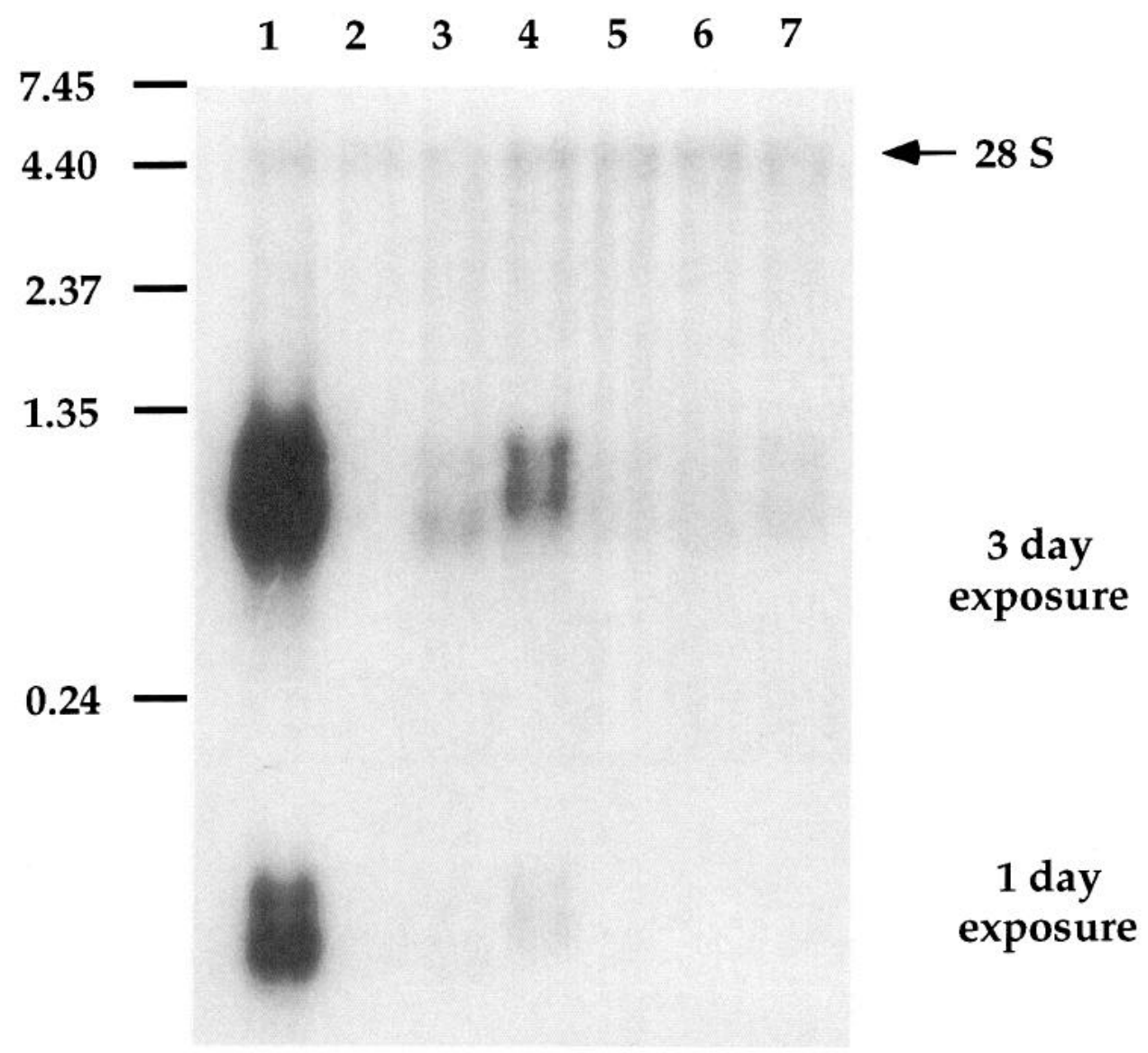

B

\section{$\begin{array}{lllllllllllllllll}1 & 2 & 3 & 4 & 5 & 6 & 7 & 8 & 9 & 10 & 11 & 12 & 13 & 14 & 15 & 16\end{array}$}

$\mathrm{Kb}$

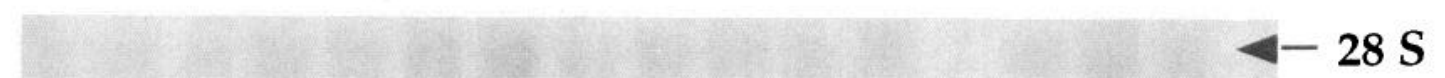

$1.77=$
$1.52=$
$1.28=$
$0.78=$
$0.63=$
$0.40-$

Figure 4. Distribution of the RNA doublet within various rat tissues by Northern blot analysis using full length cRNA (nucs. 42-800) as a hybridization probe. $A$, Autoradiograph representing analysis of rat brain total RNA; $5 \mu \mathrm{g}$ of total RNA was analyzed from the following brain regions: 1 , hypothalamus; 2 , cerebellum; 3 , hindbrain; 4 , midbrain/thalamus; 5 , hippocampus; 6 , striatum; and 7 , cortex. $B$, Autoradiograph representing analysis of rat peripheral tissue total RNA; $5 \mu \mathrm{g}$ of total RNA was analyzed from the following brain regions: 1 , striatum (from cocaine treated animals); 2, heart; 3 , liver; 4 , spleen; 5 , kidney; 6 , testis; 7 , lung; 8 , tongue; 9 , epididymis; 10 , small intestine; 11 , muscle; 12 , adrenal gland; 13 , pancreas; 14 , submaxillary gland; 15 , thymus; and 16 , eye. 


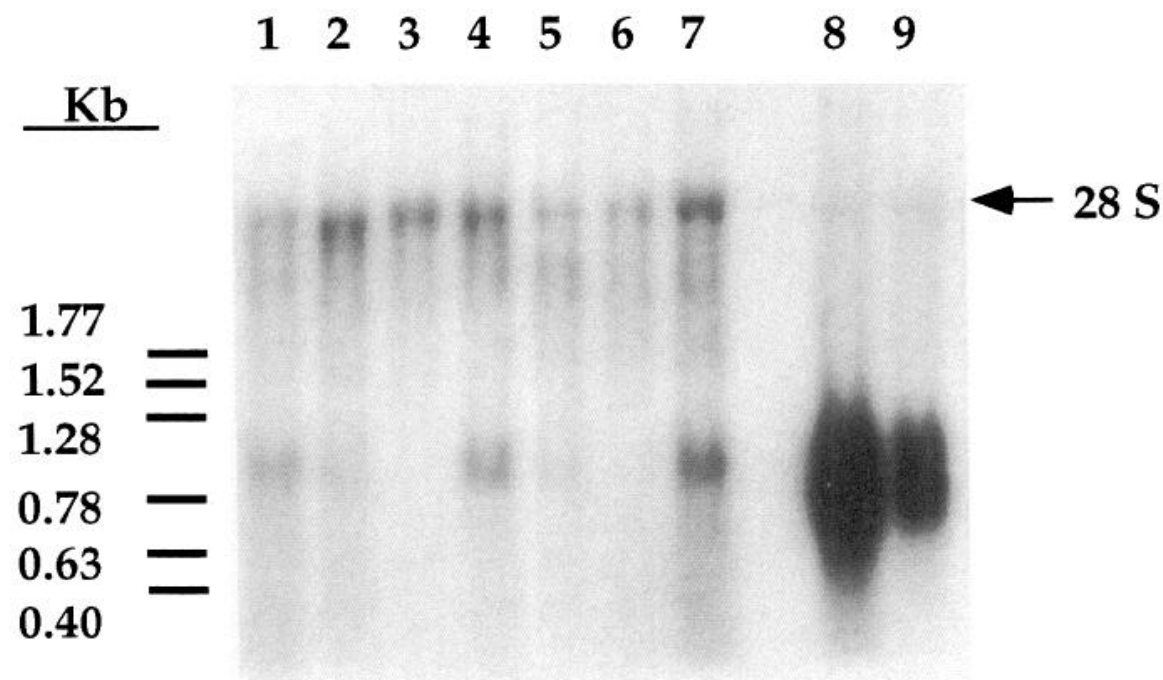

cRNA probe are specific, and represent cells expressing the RNA doublet.

\section{Discussion}

PCR differential display is a recently described technique which allows for the microanalysis of transcriptional changes occurring in a given cell or tissue (Liang and Pardee, 1992; Bauer et al., 1993; Liang et al., 1993). The study described here has focused on the identification of brain (striatum, cerebellum, and hippocampus) transcripts whose relative levels are regulated following acute administration of the psychomotor stimulants, cocaine and amphetamine. Ninety-six individual PCR differential display reactions were performed using 12 different $3^{\prime}$ primers and 8 different $5^{\prime}$ primers. Over 12,000 PCR products were generated, and less than $0.05 \%$ of the observed bands exhibited profiles indicative of transcriptional regulation by cocaine or amphetamine. Thus, acute psychomotor stimulant administration appears to affect transcription of an extremely limited array of genes within the brain structures examined, and clearly does not induce wholesale transcriptional effects within the $60 \mathrm{~min}$ time frame examined.

One PCR product was identified which represents an mRNA doublet whose relative striatal levels are increased four- to fivefold by both acute cocaine and amphetamine treatment. This observation led us to investigate the effects of another addictive drug, morphine, on transcriptional expression in various rat brain regions (data not shown). Acute morphine $(10 \mathrm{mg} / \mathrm{kg}$, with animals sacrificed $60 \mathrm{~min}$ following injection) had no apparent effect on RNA doublet levels within the striatum, cortex, hypothalamus, hindbrain, midbrain, or hippocampus. Chronic morphine administration (one $75 \mathrm{mg}$ morphine pellet implanted daily for $7 \mathrm{~d}$ ), and naloxone-precipitated morphine withdrawal (60 min post $0.1,1$, and $100 \mathrm{mg} / \mathrm{kg}$ naloxone administration) also had no observable effect on RNA doublet levels. Thus, modulation of the catecholaminergic system appears to control RNA doublet levels in the striatum only, with modulation of the opioid system having no observable effect on neuronal transcription.

cDNA sequence analysis characterized the rat mRNA corresponding to the striatal, psychomotor stimulant regulated PCR product. At least two distinct transcriptional events occur in a differential fashion to generate multiple species of mRNA from a unique primary transcript. One such event involves differential polyA site utilization. The polyA addition event presumably oc- curs approximately equally at the two AATAAA sites noted in Figure 3, as transcriptionally active tissues contain nearly equivalent levels of the 700 and 900 base transcripts. The corresponding human transcript, though, is present as a single 900 base species, suggesting that the upstream polyA addition site is either not present or not utilized within the primary transcript. Differential exon splicing represents a second type of transcriptional event producing multiple species of mRNA. Unlike differential polyA site utilization, this event is predicted to effect the ultimate translation product, as the alternately spliced 39 base sequence element is located within the putative protein coding region. Approximately one-third (5 of 16) of the cDNA clones examined which span this region contained the $39 \mathrm{bp}$ insert. Also, Northern blot analysis of rat midbrain and hypothalamic total RNA using a radiolabeled oligonucleotide complementary to the $39 \mathrm{bp}$ insert showed that the sequence element is present in both the 700 and 900 base transcripts in both tissues (data not shown). Thus, nuclear factors which determine apparent alternate splicing do not appear to be coupled to events determining polyA site utilization.

Northern blot analysis identified the rat brain regions and peripheral tissues which express the RNA doublet. A limited profile of expression was observed, with the hypothalamus and pituitary representing the major sites of transcriptional expression. The midbrain/thalamus and eye also contained relatively abundant levels of the RNA doublet. Other brain regions, as well as the adrenal, contained small yet detectable levels of the transcript. This pattern of expression is suggestive of a potential functional role of the predicted protein product within the neuroendocrine system. Expression within human brain was qualitatively similar to that observed for rat, indicating that the presumed protein product also plays a functional role across mammalian species. Lastly, the use of both sense and antisense strand-specific RNA probes in Northern blot analysis (data not shown) revealed that only one strand of the corresponding gene is transcribed; no hybridization signals were observed in any RNA sample tested when the sense RNA was used as a hybridization probe.

Distribution of the RNA doublet throughout the rat brain as shown by in situ hybridization was predominantly confined to hypothalamic neuroendocrine neurons and limbic neural circuits. Contributions from structures in sexual circuits and those involved in autonomic functions also exist. This unique brain dis- 

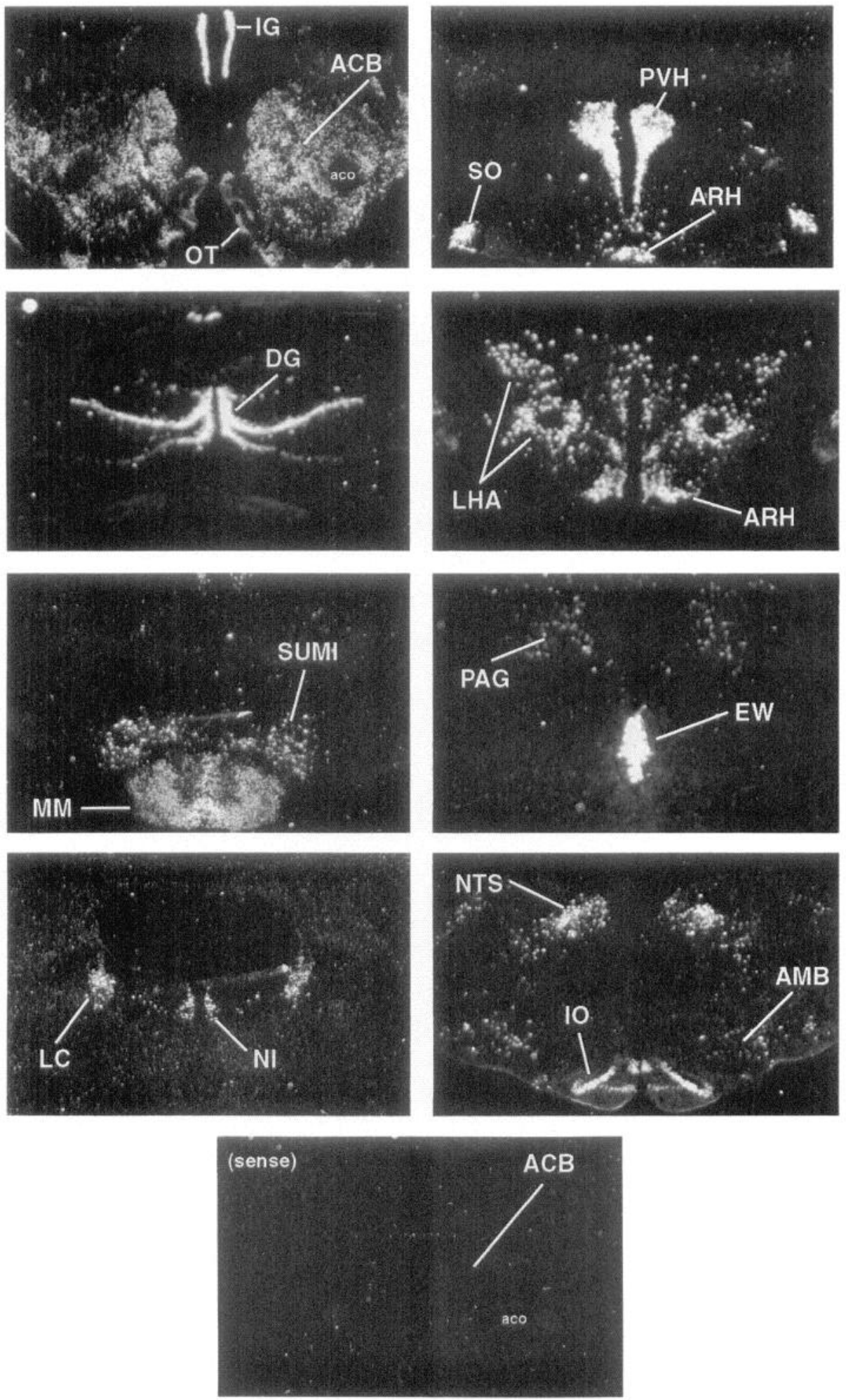

Figure 6. In situ hybridization analysis of RNA doublet expression throughout the adult rat brain. Darkfield photomicrographs are shown from coronal ( $30 \mu \mathrm{m}$ thick) sections from one animal $(n=3)$ probed with an ${ }^{35} \mathrm{~S}$ antisense cRNA hybridization probe. A section at the level of the prefrontal cortex hybridized with a sense cRNA control probe is also shown. Sections were developed $5 \mathrm{~d}$ after emulsion. $I G$, induseum griseum; $A C B$, nucleus accumbens; $O T$, olfactory tubercle; aco, anterior commissure; $P V H$, paraventricular nucleus; $S O$, supraoptic nucleus; $A R H$, arcuate nucleus; $D G$, dentate gyrus; $L H A$, lateral hypothalamic area; $M M$, mammillary nucleus; $S U M I$, supramammillary nucleus; $P A G$, periaqueductal gray; $E W$, Edinger-Westphal nucleus; $L C$, locus coeruleus; $N I$, nucleus incertus; $N T S$, nucleus of the solitary tract; $I O$, inferior olive; $A M B$, nucleus ambiguus. The rat brain atlas of Swanson (1992) was used to identify specific in situ hybridization positive cells and brain nuclei, as well as providing a nomenclature for labeling. tribution may provide some insights into a possible functional role for the encoded protein product. For example, expression of the RNA doublet is robust in the hypothalamus. Its abundance in this brain region is due, in part, to expression within neuroendocrine neurons such as the paraventricular, arcuate and supraoptic nuclei. Many neurons within these regions send afferents to, and release neuropeptides which modulate pituitary hormone secretion and regulate osmolality (Simerly, 1993).
Thus, localization of high levels of the RNA doublet to these neurons, coupled with the predicted structure of the encoded protein product(s) suggest that the transcript may encode a neuroendocrine secretogogue.

Another possible role for the putative encoded protein is suggested by expression of the RNA doublet in limbic neural circuits. For example, the transcript is present within the amygdaloid complex, dentate gyrus of the hippocampus, and the 
hypothalamic mammillary nucleus and supramammillary nucleus. Expression within the neostriatum is unique by its confinement to the nucleus accumbens and relative absence from the caudoputamen. The nucleus accumbens mediates the reinforcing and rewarding properties of drugs of abuse (Koob, 1992). Furthermore, the striatum is the only brain region that exhibited upregulation of RNA doublet levels following acute cocaine and amphetamine administration. It remains to be determined whether cocaine and amphetamine regulation of RNA doublet expression in the neostriatum is confined to the nucleus accumbens. Such a limited pattern of expression throughout neostriatal, hypothalamic, and amygdaloid components of the limbic neural circuits suggest a possible role in reward processes and affect.

The remaining areas of the rat brain exhibiting RNA doublet expression are limited, yet may provide additional clues as to a putative function. For example, moderate levels of expression are seen in two nuclei which represent major sexual neural circuits-the ventral premammillary nucleus of the hypothalamus, and the posterior dorsal aspect of the medial nucleus of the amygdala (which receives afferents from the former structure). The ventral premammillary nucleus receives inputs from sexually dimorphic brain regions and has been implicated in mediating reproductive behavior and physiology as well as aggressive behavior (Simerly, 1993). RNA doublet expression is also observed within sites that modulate autonomic functions. Neurons of the nucleus solitary tract and inferior olive contain moderate to weak levels of the RNA doublet. Noradrenergic neurons of the brainstem such as the locus coeruleus and cells within the A 1/C1 region of the ventrolateral medulla express the transcript. The locus coeruleus projects extensively throughout the brain and spinal cord and participates in arousal states (Aston-Jones et al., 1984).

cDNA sequence analysis predicts the translation of a protein either 129 or 116 amino acids in length, depending on the presence or absence of the 39 base in-frame sequence element. Furthermore, polysume analysis (data not shown) indicates that the RNA doublet is efficiently and actively translated in the hypothalamus in vivo, with in vitro translation (data not shown) resulting in the generation of protein products whose observed apparent molecular mass correlates with those predicted solely from nucleotide sequence analysis. Additional computer analysis (employing the BLAST alignment program; Altschul et al., 1990) of the predicted proteins against the 113,000 protein sequences contained within the NIH data base revealed no significant homology. The most noteworthy property of the predicted proteins is the presence of a hydrophobic amino terminal domain. Nineteen of the initial 27 residues are hydrophobic, representing the only region of the predicted protein constituting a major hydrophobic domain. Furthermore, the overall structure of this region corresponds to that of a signal peptide motif (Lingappa and Blobel, 1980; van Heijne, 1990), and suggests that the protein products are targeted for secretion following synthesis. Another potentially significant observation is the presence of multiple paired hasic amino acid residues ( $R R, K R, R K$, and $K K$ ) located throughout the predicted protein sequence. Such sites represent those recognized by various neuroendocrine protein convertases (Steiner et al., 1992). Thus, the possibility arises that the predicted protein may be a substrate target for posttranslation proteolytic cleavage events.

In summary, PCR differential display represents an excellent means by which to screen for those species of RNA which are transcriptionally regulated in distinct brain regions following acute administration of psychomotor stimulants. Presumably, the technique could also be successful in identifying transcriptionally regulated RNAs following animal paradigms for tolerance, dependence, sensitization, and withdrawal, and could further be extended to studies involving other addictive drugs such as opiates and nicotine. Additional studies along these lines could thus serve to establish a database of those specific RNAs and protein products which play a role in the establishment and maintenance of neural events associated with plasticity following both shortand long-term drug treatment.

\section{References}

Altschul SF, Gisg W, Miller W, Myers EW, Lipman DJ (1990) Basic local alignment search tool. J Mol Biol 215:403-410.

Aston-Jones G, Foote SL, Bloom FE (1984) Anatomy and physiology of the locus coeruleus neurons: functional implications. In: Norepinephrine: frontiers in clinical science (Ziegler M, Lake C, eds), pp 92-116. Baltimore: Williams and Wilkins.

Bauer D, Muller H, Reich J, Reidel H, Ahrenkiel V, Warthoe P, Strauss M (1993) Identification of differentially expressed mRNA species by an improved display technique (DDRT-PCR). Nucleic Acids Res $21: 4272-4280$.

Chomczynski P, Sacchi N (1987) Single-step method of RNA isolation by acid quanidinium thiocyanate-phenol-chloroform extraction. Anal Biochem 162:156-159.

Clark M, Post RM, Weiss SRB, Nakajima T (1992) Expression of c-fos mRNA in acute and kindled cocaine seizures in rats. Brain Res 582: 101-106.

Curran T, Gordon MB, Rubino KL, Sambucetti LC (1987) Isolation and characterization of the c-fos(rat) cDNA and analysis of posttranslational modification in vitro. Oncogene 2:79-84.

Dragunow M, Logan B, Laverty R (1991) 3,4 Methylenedioxymethamphetamine induces Fos-like proteins in rat basal ganglia: reversal with MK-801. Eur J Pharmacol 206:255-258.

Gawin FH (1991) Cocaine addiction: psychology and neurophysiology. Science 251:1580-1586.

Glowinski J, Iversen LL (1966) Regional studies of catecholamine in the rat brain: the disposition of $\left[{ }^{3} \mathrm{H}\right]$ norepinephrine, $\left[{ }^{3} \mathrm{H}\right]$ dopamine, and $\left[{ }^{3} \mathrm{H}\right] \mathrm{DOPA}$ in various regions of the brain. J Neurochem 13:665669.

Graybiel $\Lambda$ M, Moratella R, Robertson HA (1990) Amphetamine and cocaine induce drug-specific activation of the $c$-fos gene in striosomematrix compartments and limbic subdivisions of the striatum. Proc Natl Acad Sci USA 87:6912-6916.

Hope B, Kosofsky B, Hyman SE, Nestler EJ (1992) Regulation of immediate early gene expression and AP-1 binding in the rat nucleus accumbens by chronic cocaine. Proc Natl Acad Sci USA 89:57645768 .

Iadarola MJ, Chuang EJ, Yeung C-L, Hoo Y, Silverthorn M, Gu J, Draisci G (1993) Induction and suppression of proto-oncogenes in rat striatum after single and multiple treatments with cocaine and GBR-12909. In: NIDA research monograph series, Vol 125, Activation of immediate early genes by drugs of abuse (Grzanna $R$, Brown RM, eds), pp 181-211.

Koob GF (1992) Drugs of abuse: anatomy, pharmacology and function of reward pathways. Trends Neurosci 13:177-184.

Kozak M (1989) The scanning model for translation: an update. J Cell Biol 108:229-241.

Kuhar MJ, Boja MC, Ra JW (1991) The dopamine hypothesis of the reinforcing properties of cocaine. Trends Neurosci 14:299-302.

Liang P, Pardee AB (1992) Differential display of eukaryotic messenger RNA by means of the polymerase chain reaction. Science 257 : 967-971.

Liang P, Averboukh L, Pardee AB (1993) Distribution and cloning of eukaryotic mRNAs by means of differential display: refinements and optimization. Nucleic Acids Res 21:3269-3275.

Lingappa VR, Blobel G (1980) Early events in the biosynthesis of secretory and membrane proteins: the signal hypothesis. Rec Prog Hormone Res 36:451 475 .

Nestler EJ (1992) Molecular mechanisms of drug addiction. J Neurosci $12: 2439-2450$.

Nguyen TG, Kosofsky BE, Birnbaum R, Cohen BM, Hyman SE (1992) Differential expression of c-Fos and Zif-268 in rat striatum after halo- 
peridol, clozapine and amphetamine. Proc Natl Acad Sci USA 89: $4270-4274$.

Simerly RB (1994) Anatomical substrates of hypothalamic integration. In: The rat nervous system (Paxinos G, ed), in press. New York: Academic.

Simmons DM, Arriza JL, Swanson LW (1989) A complete protocol for in situ hybridization of messenger RNAs in brain and other tissues with radiolabelled single-stranded RNA probes. J Histotechnol 12: 169-181.
Steiner DF, Smeekens SP, Ohagi S, Chan SJ (1992) The new enzymology of precursor processing endoproteases. J Biol Chem 267: 23435-23438.

Swanson LW (1992) Brain maps: structure of the rat brain. New York: Elsevier.

von Heijne G (1990) The signal peptide. J Membr Biol 115:195-201. Young ST, Porrino LJ, Iadarola MJ (1991) Cocaine induces striatal c-fos-immunoreactive proteins via dopaminergic D1 receptors. Proc Natl Acad Sci USA 88:1291-1295. 